\title{
Evaluation of 2\% Chlorhexidine and 2\% Sodium Fluoride as Endodontic Irrigating Solutions on Root Dentine Microhardness: An In Vitro Study
}

\author{
Sangeeta Kulkarni ${ }^{1}$ Mohammed Mustafa ${ }^{2, \odot}$ Kiran Ghatole ${ }^{1} \quad$ Ali Robaian AlQahtani $^{2}$ \\ Faris Yahya I. Asiri ${ }^{3}$ Ziyad Ibrahim Alghomlas ${ }^{4}$ Tameem Abdullah Alothman ${ }^{5}$ Fawaz Fahad Alhajri ${ }^{6}$
}

${ }^{1}$ Department of Conservative Dentistry and Endodontics, Al-Badar Dental College and Hospital, Kalaburagi, Karnataka, India

${ }^{2}$ Department of Conservative Dental Sciences, College of Dentistry, Prince Sattam bin Abdulaziz University, Al-Kharj, Saudi Arabia

${ }^{3}$ Department of Preventive Dental Sciences, College of Dentistry, King Faisal University, Al-Ahsa, Saudi Arabia

${ }^{4}$ General Dental Practitioner, Riyadh, Saudi Arabia

${ }^{5}$ General Dental Practitioner, Al-Delam, Saudi Arabia

${ }^{6}$ General Dental Practitioner, Al-Kharj, Saudi Arabia
Address for correspondence Mohammed Mustafa, BDS, MDS, Department of Conservative Dental Sciences, College of Dentistry, Prince Sattam bin Abdulaziz University, P.O.Box: 173, Al-Kharj 11942, Kingdom of Saudi Arabia (e-mail: ma.mustafa@psau.edu.sa).

Eur J Dent 2021;15:253-258

\begin{abstract}
Keywords

- chlorhexidine

- EDTA

- microhardness

- sodium fluoride

- sodium hypochlorite

- Vickers' indenter

Objectives The aim of this study was to evaluate the effects of $2 \%$ chlorhexidine gluconate $(\mathrm{CHG})$ and $2 \%$ sodium fluoride $(\mathrm{NaF})$ as endodontic irrigants on microhardness of root dentin.

Materials and Methods In this in vitro study, access cavity and root canal preparations were done on 24 freshly extracted anterior teeth. After sectioning into 24 dentin discs using hard tissue microtome in $2 \mathrm{~mm}$ thickness, all samples were immersed in solutions of $17 \%$ ethylenediamine tetra-acetic acid (EDTA) ( 2 minutes) followed by $2.5 \%$ of sodium hypochlorite ( $\mathrm{NaOCl}$ ) (10 minutes). Then samples were randomly divided into three groups based on the irrigant used: Group I: saline (control group); Group II: 2\% NaF; Group III: 2\% CHG for two minutes each. Dentin microhardness was measured before (pretreatment), during (after treatment with $17 \% \mathrm{EDTA}$ and $2.5 \% \mathrm{NaOCl}$ ), and after the experimental period (after treatment with saline, $2 \% \mathrm{NaF}$, and $2 \% \mathrm{CHG}$ ) using a Vickers indenter. Statistical evaluation of the data was done using one-way analysis of variance (ANOVA) and the Student's $t$-test, and the values are tabulated.

Results Specimens rinsed in 2\% CHG showed a significant increase in Vickers hardness number $(\mathrm{VHN})$ values $(p<0.05)$, as compared with EDTA and $\mathrm{NaOCl}$ groups, whereas saline and $2 \% \mathrm{NaF}$ groups showed no significant difference.

Conclusions NaF did not show any significant effect on microhardness of the root dentin. CHG as an irrigant was seen to have a strengthening effect on dentin microhardness in comparison to $\mathrm{NaOCl}$ and EDTA, which has decreased the strength of root dentin.
\end{abstract}

\section{Introduction}

The strength of remaining dentin in the crown and root as well as better quality of postendodontic restoration is responsible for achieving treatment of root canal in a successful

published online October 8, 2020
DOI https://doi.org/

$10.1055 / \mathrm{s}-0040-1717053$ ISSN 1305-7456. manner. ${ }^{1}$ It includes that a tooth is subjected for loss of radicular as well as coronal tissue because of performed endodontic treatment, pathology, or restorative processes previously. ${ }^{1}$ However, it has been analyzed that different root canal irrigants have dissolution effects, which results into

(C) 2020. European Journal of Dentistry.

This is an open access article published by Thieme under the terms of the Creative Commons Attribution-NonDerivative-NonCommercial-License, permitting copying and reproduction so long as the original work is given appropriate credit. Contents may not be used for commercial purposes, or adapted, remixed, transformed or built upon. (https://creativecommons.org/licenses/by-nc-nd/4.0/) Thieme Medical and Scientific Publishers Pvt. Ltd., A-12, 2nd Floor, Sector 2, Noida-201301 UP, India 
softened dentin which is considered as nonsupportive and weak structural manner that tends for fracture easily. ${ }^{2}$

It is observed that there are different types of risk factors in regard to fracture predilection for teeth that is treated endodontically among which endodontic irrigants as well as medicaments have important role on dentin. ${ }^{3}$ It is necessary to carry out elimination of necrotic and vital remnants related to microorganisms, microbial toxins, and pulp tissues from the root canal system in respect of attaining success of endodontic treatment, ${ }^{4-6}$ the complete cleaning and shaping of the root canal is not possible due to the nature of root canal anatomy which is intricate. Meanwhile, it has been evaluated that irrigation can be considered as a significant part of root canal debridement as it is responsible for allowing to clean beyond about the aspects that might not be attained completely via the instrumentation of root canal alone. ${ }^{7-10}$ In the context of history, it is observed that an aqueous solution of countess compounds can be utilized either as a subsequent or final rinse solution, or as a primary rinse solution. ${ }^{11-13}$

The canal irrigant that is most widely utilized is sodium hypochlorite $(\mathrm{NaOCl})$. It can be used at different levels of concentrations that are in the range of 0.5 to $5.25 \%$. Basically, this irrigant has an effective property of disinfecting as well as dissolving tissues, and it can be considered as a cytotoxic compound for peri-radicular and vital tissues, respectively. ${ }^{14}$ Meanwhile, it is observed that an amorphous layer has been formed which is called as a smear layer and deposited on the walls of root canal at the time of biochemical instrumentation. Besides the fact that $\mathrm{NaOCl}$ is considered as the most desirable single endodontic irrigant, it has been evaluated that it is not efficient in respect of dissolving inorganic dentin particles which is known as an element smear layer developed with the help of root canal instrumentation. ${ }^{14}$ However, it includes the fact that around $17 \%$ ethylenediamine tetra-acetic acid (EDTA) can be used in a combination with $\mathrm{NaOCl}$ in respect of gaining a synergistic effect..$^{15}$ This compound is known be a chelating agent which is helpful in the removal of calcium ions for demineralization of an inorganic element of dentine. EDTA cannot be used alone as it cannot facilitate the removal of smear layer in a complete way. Moreover, it is observed that using a combination of EDTA and $\mathrm{NaOCl}$ is suitable in terms of removing both the organic as well as inorganic components in an effective manner. ${ }^{16,17}$

The salt chlorhexidine is being used historically since 1950s as an oral antiseptic substance for toothpaste, chewing gum, and mouthwash. ${ }^{18}$ This compound is prescribed by dentists as a potential irrigant, attributable for its unique capability to bind dentin. It is known to be an effective antimicrobial agent along with having substantivity in the root canal system as well as relevant noncytotoxic. ${ }^{19}$ It is observed that fluoride can be considered an instrumental element in caries prevention along with its property of high affinity in respect of calcified tissues. Meanwhile, it has been analyzed that limited scientific data are available in regard to long-term utilization of fluoride, about its impact on patterns of dentin mineralization, as well as microhardness. It is known to have vital significance in order study about the effects of fluoride on microhardness that has potential in terms of influencing the quality of tooth along with its strength as well as integrity. ${ }^{20}$ However, it includes the compound of sodium fluoride (NaF) which is famous for its effects regarding demineralization on initial lesions of carious and bleached teeth. ${ }^{21}$ Furthermore, the given research has been performed to analyze the role of $\mathrm{NaF}$ as a root canal irrigating solution by considering the beneficial impacts of this compound on dentin.

The investigation related to physical properties of substances and measurement of hardness of teeth can be performed with the help of microhardness tests. It includes the study about microhardness of the root surface of a tooth and is considered as vital due to its suggestion about wear suffered through the root surfaces at the time of irrigation processes with several irrigants being used during the root canal treatment. ${ }^{1}$ Meanwhile, it includes the most common method that can be used for conducting the evaluation of microhardness of root canal dentin that is known as Vickers microhardness test. As per this study, it has been found that hardness number can be defined with the help of ration among indentation load and the area of residual impressions which generally depends upon the indenter shape. ${ }^{22}$

Ideally, an irrigant should exhibit all the favorable characteristics without altering the physical and chemical properties of dentin. But studies show that these commonly used irrigating solutions might yield adverse effects in the physical and chemical properties of dentin, including its microhardness. Hence, it is suggested that sound reasoning of not only which chemicals and at what concentrations eliminates the microbes, but also their effects on the biological substrate (root dentin) and their consequences are important to strike a predictable success in endodontic treatment. Thus, the aim of this in vitro study was to evaluate the effect of $2 \%$ chlorhexidine gluconate $(\mathrm{CHG})$ and $2 \% \mathrm{NaF}$ as endodontic irrigating solutions on microhardness of root dentin.

\section{Materials and Methods}

This is an in vitro study conceptualized in the collaboration between three teaching Institutions/Universities, that is, (1) Rajiv Gandhi University of Health Sciences, Bengaluru, Karnataka, India, (2) Prince Sattam Bin Abdulaziz University, Al-Kharj, Saudi Arabia, and (3) King Faisal University, Al-Ahsa, Saudi Arabia). This experiment was conducted in the department of conservative dentistry and endodontics Al-Badar Rural Dental College and Hospital, Kalaburagi, Rajiv Gandhi University of Health Sciences, Bengaluru, Karnataka, India. This being an in vitro study, Institution Ethical Clearance (IEC) was not required. In our college, IEC is provided only for in vivo studies; however, permission was obtained from the concerned committee of the college before the commencement of the study. For the purpose of standardization, 24 freshly extracted central incisors and canines were selected, which were extracted for periodontal and traumatic reasons. The selected teeth were collected over a period of time and stored in $10 \%$ formalin at room temperature until the study was conducted. It was ensured that there was an absence of any cracks or carious defects, especially within the root portions of all the selected teeth. Debris and soft tissue remnants on the root surfaces were cleaned with a sharp 
scalpel; care was taken to ensure no excessive force were exerted while cleaning, and specimen were also inspected for cracks thoroughly after cleaning.

Irrigating solutions that were used in the study include:

1. $2.5 \% \mathrm{NaOCl}$.

2. $17 \%$ EDTA.

3. Normal saline.

4. NaF: $2 \% \mathrm{NaF}$ was prepared by diluting a measured amount of $2 \mathrm{mg}$ of crystals of $\mathrm{NaF}$ salt with $200 \mathrm{~mL}$ of distilled water to produce a concentration of $2 \% \mathrm{NaF}$.

5. $2 \% \mathrm{CHG}$.

\section{Vickers Indenter}

Dentin microhardness was measured before the specimens were subjected to the irrigants, during, and after the experimental period using Vickers indenter. The pyramidal probe marked a diamond-shaped indentation on the dentin surface with a load of $200 \mathrm{gm}$ for a dwell time of 20 seconds at 500 and $1,000 \mu \mathrm{m}$ from the pulp dentin interface. The average length of the two diagonals was used to calculate the microhardness by the inbuilt software of the Vickers indenter.

\section{Preparation of the Specimen}

After conventional access preparation, pulp tissues were extirpated from the central incisors and canines. Step back technique was used to enlarge the root canals up to size \#50 K File (DENTSPLY Maillefer). The coronal and middle thirds of all canals were flared with no. 3 Gates-Glidden drills. During instrumentation, the root canals were copiously irrigated with normal saline for each file used. Upon completion of the endodontic preparation, the teeth were sectioned transversally from the middle third of the root in $2 \mathrm{~mm}$ thickness using hard tissue microtome to produce a total of 24 dentin discs. The specimens were mounted in acrylic resin, leaving their dentin exposed to facilitate the irrigation procedures. The dentin surface of the mounted specimens was then grounded flat and smooth with a series of silicon carbide abrasive sandpaper discs (500; 800; 1,000; 1,$200 ; 1,500$; and 2,000 grit) under distilled water. Next, the mounted dentin discs were polished with the composite polishing kit. Thus, it was ensured that all the specimen were smooth without cracks or any other surface defects.

\section{First Phase of the Experiment (After Treatment with $17 \%$ EDTA and $2.5 \% \mathrm{NaOCl}$ )}

The experiment was conducted in two phases. During the first phase, the microhardness of the specimens was first measured with Vickers indenter at the baseline before subjecting to any irrigants. The entire specimens were immersed in solutions of $17 \%$ EDTA ( 2 minutes) followed by $2.5 \%$ of $\mathrm{NaOCl}$ ( 10 minutes). The microhardness of these specimens was measured with Vickers indenter after washing away the remnants of EDTA and $\mathrm{NaOCl}$ with normal saline. Vickers hardness number (VHN) for specimens at the baseline and after treating with $17 \%$ EDTA and $2.5 \% \mathrm{NaOCl}$ were tabulated. The values are represented in - Table 1. Generalized reduction in microhardness in specimens treated with EDTA and $\mathrm{NaOCl}$ was noted. The diamond-shaped indentations obtained on the dentin surface
Table 1 Mean value, standard deviation (SD), and t-value of surface hardness measurements (VHN) before treatment (control group) and after treatment with 17\% EDTA and 2.5\% NaOCl

\begin{tabular}{|l|l|l|}
\hline & $\begin{array}{l}\text { Pretreated (control } \\
\text { group)/before the } \\
\text { treatment }\end{array}$ & $\begin{array}{l}\text { After treatment } \\
\text { (group) with 17\% EDTA } \\
\text { and 2.5\% NaOCl }\end{array}$ \\
\hline Mean & 50.32 & 47.7693 \\
\hline SD & 2.3903 & 4.0581 \\
\hline$t$-value= 2.8736 &
\end{tabular}

Abbreviations: EDTA, ethylenediamine tetra-acetic acid; $\mathrm{NaOCl}$, sodium hypochlorite.
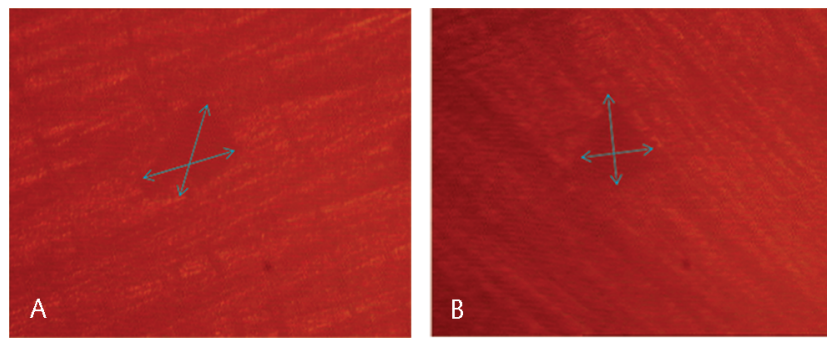

Fig. 1 (A) Pretreatment control group. (B) Group treated with ethylenediamine tetra-acetic acid (EDTA) and sodium hypochlorite ( $\mathrm{NaOCl}$ ).
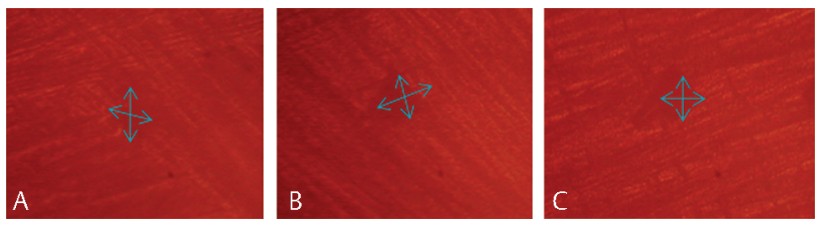

Fig. 2 (A) Group I-control/saline. (B) Group II-treated with $2 \%$ sodium fluoride (NaF). (C) Group III-treated with $2 \%$ chlorhexidine gluconate $(\mathrm{CHG})$.

of the specimen of the control group and the group treated with EDTA and $\mathrm{NaOCl}$ is shown in - Fig. 1A and 1B .

\section{A Second Phase of the Experiment (After Treatment with Saline, 2\% NaF, 2\% CHG)}

Specimens randomly divided into three groups:

1. Group I control group, was immersed in saline $(n=8)$

2. Group II treated with $2 \% \mathrm{NaF}(n=8)$

3. Group III treated with $2 \% \mathrm{CHG}(n=8)$

All the groups were immersed in the irrigating solutions for two minutes and the microhardness of these specimens were measured with Vickers indenter similarly as described above. Representative images of VHN indentations for specimens after treating with saline, $2 \% \mathrm{NaF}$, and $2 \% \mathrm{CHG}$ are shown in figures (-Fig. 2A-C).

\section{Results}

Statistical evaluation of the data was done using the one-way analysis of variance (ANOVA) and the Student's t-test. Sample size was restricted to less than 30 , so that paired $t$-test can be applied for comparison for two groups. A total of $95 \%$ was the power of the study, and $5 \%$ was the level of significance. 
The data were tabulated for statistical analysis using the SPSS computer software. A descriptive analysis was computed as the frequency of each score for each tested group. Comparative VHN values for pretreated (control group) and after-treated group with $17 \%$ EDTA and $2.5 \% \mathrm{NaOCl}$, the mean value, standard deviation (SD), and t-values of specimens before and after treatment with EDTA and $\mathrm{NaOCl}$ was calculated and the $t$-value was 2.8736 as shown in (-Table $\mathbf{1}$ ).

\section{Inference}

1. The calculated $t$-value exceeds the critical value (2.8736>2.16), so the means are significantly different.

2. Group treated with EDTA and $\mathrm{NaOCl}$ showed a statistically significant difference in VHN, as there is a decrease in microhardness when compared with the pretreatment (control group).

Here $t$-value obtained was statistically significant. Therefore, there is a significant difference in microhardness values of the specimen calculated before the experiment and on treating with EDTA and $\mathrm{NaOCl}$, indicating dentin demineralization due to demineralizing effects of both the irrigants (EDTA and $\mathrm{NaOCl}$ ).

Specimens that have been randomly divided into three groups, with each group consisting of eight random specimens are shown in - Table 2. Mean value, SD, and $t$-value in VHN for three groups, that is, after treatment with saline (control group), $2 \% \mathrm{NaF}$, and $2 \% \mathrm{CHG}$ are shown in - Table 3, and comparison and statistical analysis of all the three groups is shown in -Table 4 .

\section{Inference}

1. $t$-values of 1.18 and $0.75(<2.145$ for $p=0.05)$ for Group I and Group II were obtained, showing that there is no statistically significant difference in the VHN for Group I and Group II.

2. $t$-values of 14.48 ( $>2.145$ for $p=0.05$ ) for the third group were obtained, showing that there is a statistically significant difference of VHN in Group III.

3. The (ANOVA value) $f$-ratio value was 126.09534 , the result was significant at $P<0.05$.

4. Similarly, there was no statistically significant difference in the VHNs for Group I and Group II in comparison with the group treated with EDTA and $\mathrm{NaOCl}$.

5. But Group III showed a statistically significant difference in the VHN, as there is an increase in microhardness values in comparison with the group treated with EDTA and $\mathrm{NaOCl}$.

Thus it can be concluded that among all the groups tested, the specimens after treatment with $\mathrm{NaOCl}$ and EDTA exhibited lower hardness values in comparison with their pretreatment readings, indicating dentin mineral loss due to the demineralizing effects of both the irrigants, whereas in comparison the specimens after respective treatment with saline and $2 \% \mathrm{NaF}$ did not show any significant difference in microhardness of root canal dentin indicating a neutral effect of these irrigants on the dentin surface, whereas $2 \%$ CHG exhibits an increase in the microhardness of root canal dentin in comparison with their pretreatment readings, indicating a strengthening of the dentin surface.

Table 2 Specimens have been randomly divided into three groups, with each group consisting of eight random specimens

\begin{tabular}{|l|l|l|l|l|l|}
\hline \multicolumn{5}{|c|}{ After treatment with saline, 2\% NaF, 2\% CHG } \\
\hline $\begin{array}{l}\text { S. no. of the } \\
\text { specimen }\end{array}$ & Group I (saline) & $\begin{array}{l}\text { S. no. of the } \\
\text { specimen }\end{array}$ & Group II (2\% NaF) & $\begin{array}{l}\text { S. no. of the } \\
\text { specimen }\end{array}$ & $\begin{array}{l}\text { Group III } \\
\text { (2\% CHG) }\end{array}$ \\
\hline 1 & 59.55 & 2 & 44.39 & 3 & 70.26 \\
\hline 4 & 58.90 & 5 & 50.56 & 6 & 68.48 \\
\hline 7 & 55.98 & 8 & 44.36 & 9 & 65.21 \\
\hline 10 & 50.16 & 11 & 46.37 & 12 & 72.11 \\
\hline 13 & 50.93 & 14 & 49.16 & 15 & 67.92 \\
\hline 16 & 51.12 & 17 & 46.19 & 18 & 66.34 \\
\hline 19 & 54.62 & 20 & 48.45 & 21 & 71.23 \\
\hline 22 & 53.88 & 23 & 46.93 & 24 & 70.85 \\
\hline
\end{tabular}

Abbreviations: $\mathrm{CHG}$, chlorhexidine gluconate; NaF, sodium fluoride.

Table 3 Mean, standard deviation (SD, and t-value in the VHN for three groups (after treatment with saline (control group), $2 \%$ sodium fluoride and $2 \% \mathrm{CHG}$ )

\begin{tabular}{|l|l|l|l|}
\hline & Group I (saline) & Group II (2\%NaF) & Group III (2\% CHG) \\
\hline Mean & 54.39 & 47.05 & 69.05 \\
\hline SD & 3.59 & 2.21 & 2.46 \\
\hline$t$-value & 1.18 & 0.75 & 14.48 \\
\hline
\end{tabular}

Abbreviations: CHG, chlorhexidine gluconate; NaF, sodium fluoride; VHN, Vickers hardness number. 
Table 4 Comparison and statistical analysis of all the three groups

\begin{tabular}{|l|l|l|l|l|}
\hline & Group I (saline) & Group II (2\%NaF) & Group III (2\% CHG) & Total \\
\hline No. of samples & 8 & 8 & 8 & 24 \\
\hline Mean & 54.39 & 47.05 & 69.05 & 56.83 \\
\hline SD & 3.59 & 2.21 & 2.46 & 9.722 \\
\hline (ANOVA value) $f=126.09534$ & \multicolumn{5}{|l}{} \\
\hline
\end{tabular}

Abbreviations: ANOVA, analysis of variance; $\mathrm{CHG}$, chlorhexidine gluconate; NaF, sodium fluoride; SD, standard deviation.

\section{Discussion}

There is consistently a continuous debate going on regarding the ideal sequence of irrigants to accomplish through debridement of the root canal system. ${ }^{23} \mathrm{NaOCl}$ has been a gold standard endodontic irrigation solution which is being used since long time because of its excellent antimicrobial properties, debridement, lubrication, and dissolution of necrotic tissues. ${ }^{24,25}$ Results of the present study concludes that endodontic irrigating solutions like $\mathrm{NaOCl}$ and EDTA during cleaning and shaping of the root canal may have a direct potential effect on the root dentin surface and can alter the surface structure of the dentin. This, in turn, may reduce the clinical performance of endodontically treated teeth.

A chemical named $\mathrm{NaOCl}$ can be used for longer duration of time and is considered as a highly reactive compound for having an undesirable impact on radicular dentin. ${ }^{26}$ In the current scenario, it has been evaluated that various kinds of reports exist related to $\mathrm{NaOCl}$ to indicate about its adverse effects on several physical properties, including elastic modulus, microhardness, and flexural strength of the dentine. ${ }^{27}$ In the same way, it is observed that the EDTA solution has chelating property that is responsible for inducing excessive and adverse softening of an inorganic part of dentin as well as it is accountable for decreasing microhardness of the root canal dentin in subsequent manner. ${ }^{2}$ What happens when EDTA and $\mathrm{NaOCl}$ are used one after another? By considering a number of relevant in vitro studies, it has been identified that this dual irrigation has the potential to regime removal of organic phase $(\mathrm{NaOCl})$ and inorganic (EDTA) stage related to dentine in terms of providing the rise of effects that are undesirable accordingly. ${ }^{14}$ Dentin has the capability to become soft due to influence of dissolution impact of different root canal irrigants which is structural nonsupportive. Thus, it can be known as imperative about the hardness of this tissue as it can be retained or enhanced. It is observed that such components are responsible for encouraging investigators for looking for alternative irrigants which can be retained the suitable for features along with lack of harmful effects of $\mathrm{NaOCl}$ at the same time. Meanwhile, it will lead to the emergence of $\mathrm{CHG}$ because if having capability in terms of using it for specific purpose. ${ }^{28}$

CHG depicts broad spectrum associated with antibacterial agent which is effectual to fight against different strains of bacteria that are found within affected root canals, but $2 \%$ CHG cannot be used as primary irrigant due to its lack of tissue dissolution properties. Although EDTA followed by $\mathrm{NaOCl}$ is still considered the primary irrigants of choice, researchers recommend that $2 \%$ CHG to be used as a final irrigant based on its property of substantivity along with its prolonged antimicrobial activity. In addition, it is also seen to have a hardening effect on root dentin, thus neutralizing the demineralizing or decalcifying effect of the various other primary irrigants. ${ }^{28}$

Matrix metalloproteinases (MMPs) denote cell-derived proteolytic enzymes which are present across dentin. A few of these function constructively while remolding tissues and mineralization of dentin. However, other MMPs can have an adverse effect on dentin. These deleterious enzymes are shown to be released after the exposure of dentin to acids and further break down the collagen matrix and degrade them. This, in turn, results in reduced bond strength and microleakage. In this study, samples were pretreated with $\mathrm{NaOCl}$ and EDTA before dividing into groups. It is hypothesized that EDTA being a chelating agent has a similar action to that of acids and stimulates the release of the MMPs and hence are responsible for reduced microhardness of dentin. ${ }^{29}$

Various studies have demonstrated the preservation of hybrid layers with $\mathrm{CHG}$ treatment after acid-etching. CHG prevents and decreases the release of MMPs by its protein inhibition action (Proteinase inhibitor). Thus we can presume that the increase in the microhardness may be attributed to the better preservation of the collagen fibrils of the dentinal surface after treatment with $2 \% \mathrm{CHG}^{30}$ The probable $\mathrm{CHG}$ utilizes endodontics that is being used by various researchers, but as such there is minimized research with reference to its utilization as a final irrigant. On the basis of this study, it is urged that further research be performed on the potentiality of $2 \% \mathrm{CHG}$ as a final irrigant.

Our present study is an in-vitro study, and so more in vivo studies will increase the substantivity of this study. In addition to this, the probability of CHG that is utilized within endodontics is clearly specified by various researchers but restricted work is done as a final irrigant. Hence, it is suggested that more research be performed on $2 \% \mathrm{CHG}$ as a final root canal irrigant.

\section{Conclusion}

It may be concluded that within certain limitations in our study, the treatment of the root surfaces with EDTA and $\mathrm{NaOCl}$ solutions reduces the microhardness of root dentine. Normal saline as an irrigant did not induce any changes in the microhardness of root canal dentin. NaF was used in this study due to its remineralizing effects on bleached teeth, but when used as an irrigant, it did not show any significant effect on the 
microhardness of root dentin. But 2\% CHG as an endodontic irrigant was seen to have a positively strengthening effect on the root dentin microhardness in comparison to $\mathrm{NaOCl}$ and EDTA, which has decreased the strength of root dentin.

\section{Conflict of Interest}

None declared.

\section{Acknowledgment}

The authors are thankful to Deanship of Scientific Research, Prince Sattam bin Abdulaziz University, Al-Kharj, Saudi Arabia for providing the financial support towards the publication cost of this article.

\section{References}

1 Kishen A. Mechanisms and risk factors for fracture predilection in endodontically treated teeth. Endod Topics 2006;13:57-83

2 Saleh AA, Ettman WM. Effect of endodontic irrigation solutions on microhardness of root canal dentine. J Dent 1999;27(1):43-46

3 Shabbir J, Qazi F, Farooqui W, Ahmed S, Zehra T, Khurshid Z. Effect of Chinese propolis as an intracanal medicament on post-operative endodontic pain: a double-blind randomized controlled trial. Int J Environ Res Public Health 2020;17(2):445

4 Siqueira JF Jr, Rôças IN. Clinical implications and microbiology of bacterial persistence after treatment procedures. J Endod 2008;34(11):1291-1301.e3

5 Wong R. Conventional endodontic failure and retreatment. Dent Clin North Am 2004;48(1):265-289

6 Basmadjian-Charles CL, Farge P, Bourgeois DM, Lebrun T. Factors influencing the long-term results of endodontic treatment: a review of the literature. Int Dent J 2002;52(2):81-86

7 Gutarts R, Nusstein J, Reader A, Beck M. In vivo debridement efficacy of ultrasonic irrigation following handrotary instrumentation in human mandibular molars. J Endod 2005;31(3):166-170

8 Svec TA, Harrison JW. Chemomechanical removal of pulpal and dentinal debris with sodium hypochlorite and hydrogen peroxide vs normal saline solution. J Endod 1977;3(2):49-53

9 Walton RE. Histologic evaluation of different methods of enlarging the pulp canal space. J Endod 1976;2(10):304-311

10 Haapasalo M, Shen Y, Wang Z, Gao Y. Irrigation in endodontics. Br Dent J 2014;216(6):299-303

11 Ali MA, Kano B, Endodontic materials: from old materials to recent advances. Advanced Dental Biomaterials. 2019;255-299

12 Mustafa M, Alaajam WH, Azeim AA, Alfayi NA, Alqobty RM, Alghannam S. Diffusion of calcium hydroxide through dentinal tubules of retreated root canals: an in vitro study. Eur J Dent 2018;12(3):386-392

13 Podar R, Kulkarni GP, Dadu SS, Singh S, Singh SH. In vivo antimicrobial efficacy of 6\% Morinda citrifolia, Azadirachta indica, and $3 \%$ sodium hypochlorite as root canal irrigants. Eur J Dent 2015;9(4):529-534
14 Goldsmith M, Gulabivala K, Knowles JC. The effect of sodium hypochlorite irrigant concentration on tooth surface strain. J Endod 2002;28(8):575-579

15 MohammadiZ,ShalaviS,JafarzadehH.Ethylenediaminetetraacetic acid in endodontics. Eur J Dent 2013;7(Suppl 1):S135-S142

16 Grande NM, Plotino G, Falanga A, Pomponi M, Somma F. Interaction between EDTA and sodium hypochlorite: a nuclear magnetic resonance analysis. J Endod 2006;32(5):460-464

17 Yassen GH, Al-Angari SS, Platt JA. The use of traditional and novel techniques to determine the hardness and indentation properties of immature radicular dentin treated with antibiotic medicaments followed by ethylenediaminetetraacetic acid. Eur J Dent 2014;8(4):521-527

18 Leonardo MR, Tanomaru Filho M, Silva LA, Nelson Filho P, Bonifácio KC, Ito IY. In vivo antimicrobial activity of $2 \%$ chlorhexidine used as a root canal irrigating solution. J Endod 1999;25(3):167-171

19 Siqueira JF Jr, Paiva SS, Rôças IN. Reduction in the cultivable bacterial populations in infected root canals by a chlorhexidine-based antimicrobial protocol. J Endod 2007; 33(5):541-547

20 Vieira A, Hancock R, Dumitriu M, Schwartz M, Limeback H, Grynpas M. How does fluoride affect dentin microhardness and mineralization? J Dent Res 2005;84(10):951-957

21 Sivapriya E, Sridevi K, Periasamy R, Lakshminarayanan L, Pradeepkumar AR. Remineralization ability of sodium fluoride on the microhardness of enamel, dentin, and dentinoenamel junction: an in vitro study. J Conserv Dent 2017;20(2):100-104

22 Martin JMH, de Almeida JB, Rosa EAR, et al. Effect of fluoride therapies on the surface roughness of human enamel exposed to bleaching agents. Quintessence Int 2010;41(1):71-78

23 Gomes-Filho JE, Aurélio KG, Costa MM, Bernabé PF. Comparison of the biocompatibility of different root canal irrigants. J Appl Oral Sci 2008;16(2):137-144

24 Ari H, Erdemir A, Belli S. Evaluation of the effect of endodontic irrigation solutions on the microhardness and the roughness of root canal dentin. J Endod 2004;30(11):792-795

25 Dioguardi M, Gioia GD, Illuzzi G, Laneve E, Cocco A, Troiano G. Endodontic irrigants: different methods to improve efficacy and related problems. Eur J Dent 2018;12(3):459-466

26 Pascon FM, Kantovitz KR, Sacramento PA. Nobre-dos-Santos M, Puppin-Rontani RM. Effect of sodium hypochlorite on dentine mechanical properties. A review. J Dent 2009;37(12):903-908

27 Grigoratos D, Knowles J, Ng YL, Gulabivala K. Effect of exposing dentine to sodium hypochlorite and calcium hydroxide on its flexural strength and elastic modulus. Int Endod J 2001;34(2):113-119

28 Pinheiro SL, Silva CC, Silva LAD, et al. Antimicrobial efficacy of $2.5 \%$ sodium hypochlorite, $2 \%$ chlorhexidine, and ozonated water as irrigants in mesiobuccal root canals with severe curvature of mandibular molars. Eur J Dent 2018;12(1):94-99

29 Moon PC, Weaver J, Brooks CN. Review of matrix metalloproteinases' effect on the hybrid dentin bond layer stability and chlorhexidine clinical use to prevent bond failure. Open Dent J 2010;4:147-152

30 Mohammadi Z, Abbott PV. The properties and applications of chlorhexidine in endodontics. Int Endod J 2009;42(4):288-302 